\title{
Painful muscle spasms complicating algodystrophy: central or peripheral disease?
}

\author{
W ROBBERECHT*, J VAN HEES*, H ADRIAENSEN $\dagger$, H CARTON* \\ From the Department of Neurology* and Pain-Relief Unit, and Department of Anaesthesiology, $\dagger$ University \\ Hospital Gasthuisberg, University of Leuven, Leuven, Belgium
}

SUMMARY A 21 year old female patient developed Südeck's atrophy of the right foot secondary to a chronic Achilles tendinitis. The condition was complicated by the occurrence of painful muscle spasms in the right leg and incontinence of urine. The spasms had characteristics of both a tonic ambulatory foot response and a spinal flexor reflex. The movements disappeared during sleep. Regional anaesthesia of the right leg made the spasms disappear both in and outside the region of anaesthesia. Backaveraging of the EEG showed the involuntary spasms to be preceded by a cortical potential similar to a readiness potential, indicating a cortical potential similar to a readiness potential, indicating a cortical component in the pathophysiology of the muscle spasms complicating Südeck's atrophy.

The pathophysiology of the condition called algodystrophy or reflex sympathetic dystrophy is far from understood. Rarely this syndrome is complicated by the appearance of involuntary movements, including painful muscle spasms. ${ }^{12}$ We recently encountered a patient with painful muscle spasms complicating a long standing Südeck atrophy. Electrophysiologic investigation was carried out to evaluate the pathophysiology of the movements and various pharmacological agents were administered to try to influence the spasms. It is proposed that cortical structures are involved in the generation of the movements and that the motor phenomena may be protective in nature.

\section{Case report}

A 21 year old right handed female complained of painful muscle spasms in the right leg. Since October 1978 she had suffered from a chronic right Achilles tendonitis treated with

\footnotetext{
Address for reprint requests: Prof. Dr H Carton, Department of Neurology, University Hospital Gasthuisberg, Herestraat 49, 3000 Leuven, Belgium.
}

Received 8 May 1987 and in revised form 3 November 1987. Accepted 9 November 1987 rest, immobilisation and various infiltrations at the ankle and in the right popliteal fossa (local anaesthetics, phenol). In 1981 a right calcaneal exostosis had been removed. A surgical procedure on the retracted tendon had been performed in 1982 to restore the mobility of the ankle joint. In September 1983 a sympathetic dystrophy at the right ankle was diagnosed and treated with physical therapy, calcitonin infusions and block of the right lumbar sympathetic ganglion, all without relief. At that time, the patient developed painful cramps of the right calf muscles; these spasms were progressive in frequency and intensity and gradually resulted in plantar flexion of foot and toes; later, flexors of the right knee and hip became involved. A surgical denervation of the lateral part of the gastrocnemius muscle was performed in 1985 , without success. Finally the spasms were so severe and frequent that they made the patient unable to walk unassisted and kept her from sleeping, although it was unclear by history whether they actually persisted during sleep. In 1986, incontinence of urine developed: intermittently small amounts of urine were lost during a muscle spasm and infrequency complete voidance of the urinary bladder was provoked. Apart from bronchial asthma, the patient denied any other medical or neurologic problem. No dystonia, tremor, myoclonus or epilepsy was noted in the family history.

On admission in March 1986 examination showed severe retraction of the right Achilles tendon. The skin over the right ankle was dystrophic with a red blue discoloration and hyperhidrosis, compatible with algodystrophy. There was diminished muscle bulk of the right lower leg and, although 
difficult to assess, a discrete paresis of dorsiflexion of the first toe on the right was noted. The right ankle jerk was absent. A small zone of dysaesthesia was found in the distal territory of the right sural nerve. Repetitive contractions of the flexors of the right foot, knee and hip of the right gluteus maximus muscle were noted: the jerks continuously appeared with more or less regular intervals. Intermittently, cocontractions of the contralateral gluteal muscles were seen. The spasms had a frequency of $0.25-0.5 \mathrm{~Hz}$ and lasted for about $0.5-1 \mathrm{~s}$. The movements could not be influenced by proprio- or extero-ceptive sensory stimuli. The patient had the impression that, intermittently, voluntary movement of the leg could delay the spasm for a few moments, but this could not be observed. The remainder of the general and neurologic examination was unremarkable.

Haematological and biochemical investigations were normal, including 24-hour urinary hydroxyproline excretion. Concentration of HVA in the CSF was $22 \mathrm{ng} / \mathrm{ml}$, of 5 -HIAA was $53 \mathrm{ng} / \mathrm{ml}$, both of which are normal values. Radiographs of the right ankle showed osteoporosis of the distal tibia and fibula, and talus: these findings were felt to be compatible with Südeck's atrophy. Technetium bone scan showed an area of increased tracer uptake in the right ankle and both knees. CT scan of the brain, radiographs and myelography of the entire spine were normal.

A contralateral lumbar sympathetic block did not give any relief. Oral diazepam and baclofen did not help. Only dantrolene made the spasms tolerable to the patient, but only at doses causing significant gastric discomfort. Intrathecal administration of baclofen $(100 \mu \mathrm{g}$, puncture at $D_{12}-L_{1}$ level) did not give any relief, nor did electrical stimulation of the dorsal columns through an implanted spinal electrode.

\section{Methods}

Electromyography (EMG), nerve conduction velocities (NCV), electroencephalography (EEG), blink reflex recordings and somatosensory evoked potentials (SSEP) were done using conventional methods. EEG backaveraging (MS20 MEDELEC) was performed with an electrode at position $C_{z}$ $(-)$ with reference to $A_{2}(+)$ according to the international 10-20 system. Filter setting was $0.01-50 \mathrm{~Hz}$. Sweep time was $2 \mathrm{~s} ., 1.4 \mathrm{~s}$. before and $0.6 \mathrm{~s}$. after the onset of EMG activity in the right biceps femoris muscle which was used as the trigger. $2 \times 64$ samples were averaged. Artefacts caused by eye blinking were ruled out by electrooculographic recording using the same trigger.

For regional anaesthesia of the right lower leg, a sphygmomanometer cuff was inflated to $500 \mathrm{mmHg}$ just above the knee (Bier block anaesthesia). Xylocain $0.5 \%$ was given IV at the ankle. After a few minutes, anaesthesia in the region distal to the cuff was obtained.

\section{Results}

$E M G$ showed signs of denervation in the right $\mathrm{m}$. tibialis anterior, $\mathrm{m}$. extensor digitorum longus and m. gastrocnemius. The Hoffman reflex could not be obtained on the right. Right tibial nerve conduction velocity was $34 \mathrm{~m} / \mathrm{s}$.

$E M G$ recordings during the spasm showed simulta- neous prolonged activation of the right triceps surae, dorsiflexors of the right foot, right hamstrings, rectus femoris, gluteus maximus, psoas, lumbar paraspinal muscles and right abdominal rectus muscle (fig 1).

During regional anaesthesia a complete block of the right tibial nerve was obtained as was shown by the disappearance of compound muscle action potential after tibial nerve stimulation. The spasms of muscles both in and out of the region of anaesthesia disappeared, although throughout the session, normal activation of the muscles outside the region of anaesthesia was possible as was shown by a normal EMG activation pattern.

Routine $E E G$ was normal.

Blink reflexes were normal in duration and amplitude and no additional late components were seen.

SSEPs obtained by tibial nerve stimulation were normal.

24-hour polygraphic recording showed that the muscle

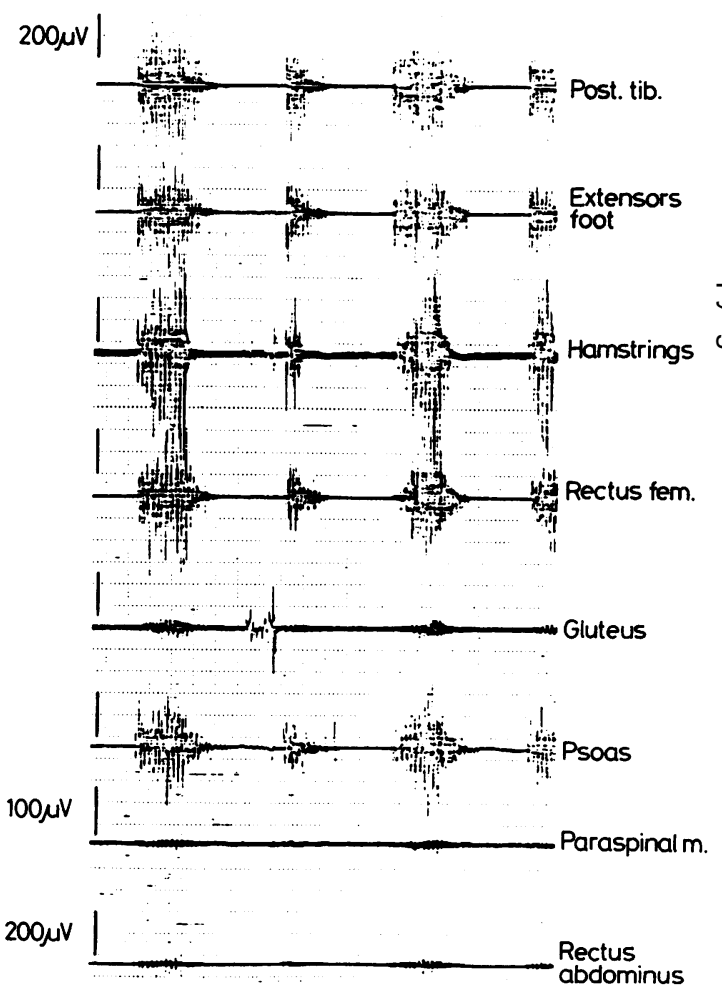

is

Fig 1 EMG recordings of the spasms: simultaneous activation of posterior tibial muscle, extensors of the foot,

hamstrings, rectus femoris, gluteus maximus, psoas muscle, paravertebral muscles and rectus abdominis muscle is shown. 

spasms completely disappeared during both REM and NREM sleep.

$E E G$ backaveraging showed the involuntary spasm to be preceded by a slow negative potential recorded at the vertex, starting $600 \mathrm{~ms}$ before onset of EMG activity and reaching a maximum amplitude of about $15 \mu \mathrm{V}$ at onset of EMG activity (fig 2a). It was followed by a slow positive activity, after which another negative deflection was secn. As the movement lasted for about 1 second and the interval between the movements was usually more than 2 seconds, it is unlikely that the preceding jerk contributed significantly to the potential recorded, considering the fact that it started $600 \mathrm{~ms}$ before the motor activation while the last movement-associated cortical potential is recorded about $300 \mathrm{~ms}$ after a movement. ${ }^{3}$ Voluntary contraction of the left biceps femoris was preceded by a slow negative potential at the vertex, identical to the one seen before the involuntary spasms (fig $2 \mathrm{~b}$ ). Owing to the frequency of the spasms, however, contamination by a potential preceding a contralateral involuntary movement was difficult to exclude. The continuous involuntary movements in the right leg made it impossible to analyse a cerebral potential preceding a voluntary movement in the same limb.

\section{Discussion}

Our patient suffered from painful muscle spasms complicating Südeck's atrophy, as previously described. ${ }^{12}$ The spasms gradually spread from the muscles of the right lower leg to the muscles of the right upper leg, gluteal and abdominal musculature. Although flexion of knee and hip are features of the spinal flexor reflex, ${ }^{4}$ the presence of plantar flexion of the ankle and toes is more suggestive of a tonic ambulatory foot response. ${ }^{5}$ The pattern of motor activation in this patient seemed to have characteristics of both these responses and was similar to the activation pattern recently described in a patient with proprioception - sensitive dystonic spasms of the leg. ${ }^{6}$

As stated in a recent review, ${ }^{7}$ involuntary movements such as tremor and chorea complicating the condition called algodystrophy, causalgia or reflex sympathetic dystrophy, have been reported ever since the original description of the syndrome. ${ }^{8}$ Recently, Marsden et $a l^{2}$ reemphasised the occurrence of movement abnormalities in algodystrophy describing five patients with painful muscle spasms and Südeck atrophy.

The pathogenesis of both algodystrophy and the motor phenomena complicating the condition is unknown. When trying to understand the mechanisms underlying the movements observed in the present patient, several pathophysiological levels have
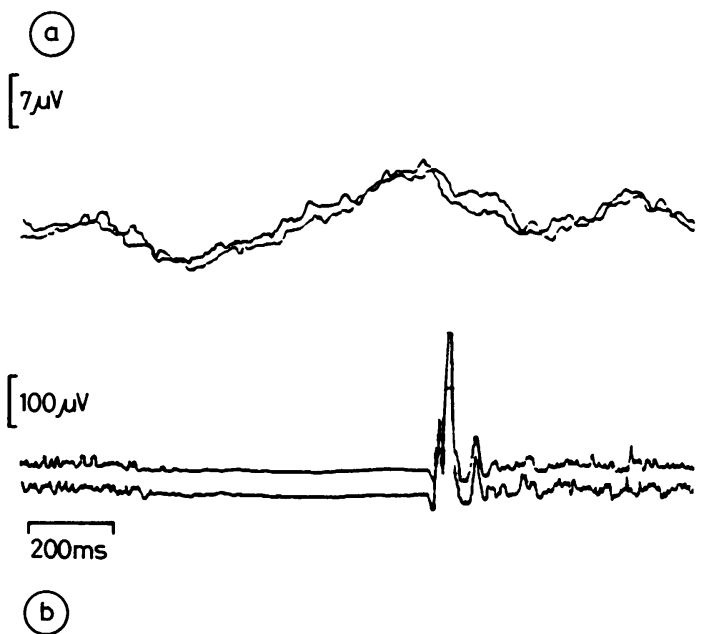

$[7 \mu v$
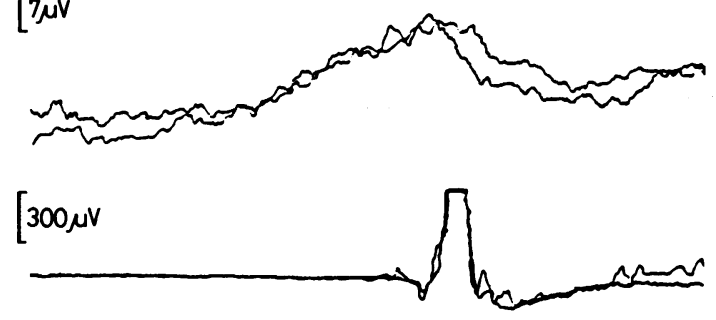

$200 \mathrm{~ms}$

Fig 2 Vertex potential preceding the involuntary spasms in the right leg $(a)$ and preceding voluntary contraction of the left biceps femoris muscle (b). EEG $\left[C_{\mathbf{z}}(-)-A_{2}(+)\right]$ was backaveraged using EMG activity in biceps femoris muscle as trigger $(2 \times 64$ samples $)$.

to be considered: (1) Can the peripheral nerve injury be responsible for the involuntary movements? (2) Is abnormal activity at the level of the spinal cord involved in the pathogenesis of the spasms? (3) Do supraspinal centres play a role in the generation of these movements?

\section{Contribution of peripheral nerve}

Clinical and electrophysiological data in our patient showed a partial lesion of the tibial nerve; damaged peripheral nerves can indeed cause involuntary movements. Rhythmic muscle activity ${ }^{10}$ and dystonic movements ${ }^{11}$ on the basis of peripheral nerve lesions have been reported. Plexus lesions can cause rhythmic myoclonus, ${ }^{12}$ and cramps and myokymia ${ }^{13}$ have been reported described following traumatic injury to a peripheral nerve. Different types of spontaneous electrical discharges have been described in injured nerves. ${ }^{14}$ 


\section{Involvement of the spinal cord}

When trying, however, to explain the pathogenesis of the movements in our patient, one has to account for the muscle activation far beyond the territory of the lesioned nerve and for the incontinence. The abnormal movements on the basis of a peripheral nerve lesion reported by Patrikios, ${ }^{9}$ Scherokman et al ${ }^{11}$ and Medina et $a l^{13}$ also involved muscles not supplied by the damaged nerve. As it is known that lesions of peripheral nerves can cause abnormal activity or sensitivity of afferent neurons, ${ }^{15-17}$ it can be postulated that the tibial nerve involved in our patient is responsible for conveying a triggering stimulus to the central nervous system and that the extended motor activation with characteristics of the spinal flexor reflex is achieved by segmental spreading of this stimulus at the level of the spinal cord. Thus, the disappearance of the spasms both in and outside the region of anaesthesia can be explained by the fact that the triggering stimulus was prevented from being generated by the local anaesthesia.

How can one explain the spasms gradually spreading from the gastrocnemius muscle to the musculature of the entire leg and abdominal wall without clear progression of the algodystrophy itself? It is well known that a lesion of a peripheral nerve can cause progressive changes in central neurons ${ }^{18} 19$ and therefore gradual spreading of the involuntary movements may be explained by progressive involvement of spinal neurons, a process which has been suggested before $^{20}$ and which may also play a role in the syndrome of painful legs and moving toes. ${ }^{21} 22$

Sleep seems to have an important modulatory influence on the involuntary movements concerned: in our patient the spasms disappeared during sleep as they did in two out of four patients described by Marsden et al. ${ }^{2}$ However, considering the profound changes occurring at multiple levels in the motor system during sleep, it is impossible to draw any conclusions from these observations. It is worth noting, however, that the abnormal movements with widespread muscle involvement induced by peripheral nerve lesions, ${ }^{913}$ have been reported to disappear during sleep, while movements confined to the territory of a single damaged nerve seem to persist during sleep. ${ }^{1012}$

\section{Involvement of cerebral structures}

Evidence is presented that cortical or subcortical structures are involved in the generation of the movements complicating the algodystrophy in our patient. The spasms were preceded by a slow cortical potential starting $600 \mathrm{~ms}$ before the motor activation. This potential was interpreted as a readiness potential. Generally such potential is related to voluntary movements. ${ }^{2324}$ In our patient no apparent difference could be seen between the activity preceding the spasms and that before voluntary flexion of the other leg. Other authors have also reported cortical potentials preceding involuntary movements: in the third patient described by Shibasaki $e t a l^{25}$ in a study on cortical discharges related to the myoclonus in Creutzfeldt-Jakob disease, a diffuse surface negative shift beginning $300 \mathrm{~ms}$ before EMG onset can be seen, as has been pointed out by Marsden $e t$ al. ${ }^{26}$ Recently Shibasaki ${ }^{28}$ reported the presence of a slow negative potential recorded at the scalp preceding the involuntary movements in choreoacanthocytosis, but not in Huntington's disease (Congress of the International Medical Society of Motor Disturbances, Lausanne, 1986).

Although it remains to be clarified what exactly such a slow potential recorded before an involuntary movement means, its presence in our patient may point to a supraspinal and even cortical component in the mechanism underlying the muscle spasms. It is of note that patient 1 described by Marsden $e t \mathrm{al}^{2}$ also had algodystrophy with involuntary movements on the basis of peripheral trauma and was successfully treated with a stereotaxic thalamotomy (nc ventralis intermedius), which is equally suggestive of supraspinal involvement in this patient. This can mean that the process underlying algodystrophy can gradually spread from the peripheral nerve to the spinal core and may finally cause changes in the organisation of the cortical and subcortical structures as has beert suggested before. ${ }^{27} \mathrm{~A}$ similar process was recently suggested by Schott $^{28}$ describing 10 cases of involuntary movements induced by peripheral trauma; it was again proposed that widespread central nervous system changes may be precipitated by peripheral lesions.

To summarise, although the underlying mech anisms remain unknown, it is concluded that cortical and subcortical structures play a role in the abnormal movements complicating the algodystrophy of the present patient.

We are indebted to Dr $\mathbf{J}$ Duyssens for his suggestions The typographical work of M Bareau is greatly appreciated.

\section{References}

1 Kleiman A. Causalgia: evidence of existence of crossed sensory sympathetic pathways fibers. Am J Surg 1954;87:839-41.

2 Marsden CD, Obeso JA, Traub MM, Rothwell JC, Kranz H Lacruz F. Muscle spasms associated with Südeck atrophy after injury. Br Med J 1984;288:173-6.

3 Tamas LB, Shibasaki H. Cortical potentials associated with movement. A review. J Clin Neurophysiol 1985;2:157-71.

4 Somjen G. Organisation of muscle and spinal reflexes. In: Somjen G, ed. Neurophysiology-The Essentials, Baltimore: Williams \& Wilkins, 1983:373-406. 
5 Manfredi M, Sacco G, Sideri G. The tonic ambulatory foot response. Brain 1975;98:167-80.

6 Berardelli A, Thompson PD, Day BL, Rothwell JC, O'Brien MD, Marsden CD. Dystonia of the legs induced by walking or passive movement of the big toe in a patient with cerebellar ectopia and syringomyelia. Neurology 1986;36:40-4.

7 Schott GD. Mechanisms of causalgia and related clinical conditions. Brain 1986;39:717-38.

8 Mitchell SW, Morehouse GR, Keen WW. (1864) Gunshot Wounds and Other Injuries of Nerves. Philadelphia, Lippincott.

9 Patrikios J. Automatisme moteur rythmique et continue après lésion d'un nerf péeriphérique. Rev Neurol (Paris) 1949; 81:932-49.

10 Said G, Bathien N. Myoclonies rythmées du quadriceps en relation avec un envahissement sarcomateux du nerf crural. Rev Neurol (Paris) 1977;133:191-8.

11 Scherokman B, Husain F, Cuetter A, Jabbari B, Maniglia E. Peripheral dystonia. Arch Neurol 1986;43:830-2.

12 Banks G, Nielsen VK, Short MP, Kowal CD. Brachial plexus myoclonus. J Neurol Neurosurg Psychiatry 1985;48:582-4.

13 Medina JL, Chokroverty S, Reyes M. Localized myokymia caused by peripheral nerve injury. Arch Neurol 1976;33:587-8.

14 . Stöhr M. Special types of spontaneous electrical activity in radiogenic nerve injuries. Muscle Nerve 1982;5:S78-S83.

15 Burchiel KJ. Effects of electrical and mechanical stimulation on two foci of spontaneous activity which develop in primary afferent neurons after peripheral axotomy. Pain 1984;18: $249-65$.

16 Wall PD, Devor M. Sensory afferent impulses originate from dorsal root ganglia as well as from the periphery in normal and nerve injured cats. Pain 1983;17:321-39.

17 Scadding SW. Development of ongoing activity, mechano- sensitivity and adrenaline sensitivity in severe peripheral nerve axons. Exp Neurol 1981;73:345-64.

18 Wall PD, Fitzgerald M, Nussbaumer JC, Van der Loos H, Devor M. Somatotopic maps are disorganized in adult rodents treated neonataly with capsain. Nature 1982;295:691-3.

19 Lisney SJW. Changes in the somatotropic organization of the cat lumbar spinal cord following peripheral nerve transection and regeneration. Brain Res 1982;259:31-9.

20 Loh L; Natian PW. Painful peripheral states and sympathetic blocks. J Neurol Neurosurg Psychiatry 1978;41:664-71.

21 Nathan PW. Painful legs and moving toes: evidence on the site of the lesion. J Neurol Neurosurg Psychiatry 1978;41:934-9.

22 Schott GD. Painful legs and moving toes: the role of trauma. $J$ Neurol Neurosurg Psychiatry 1981;44:344-6.

23 Obeso JA, Rothwell JC, Marsden CD. Simple tics in Gilles de la Tourette's syndrome are not prefaced by a normal premovement EEG potential. J Neurol Neurosurg Psychiatry 1981;44:735-8.

24 Berardelli A, Rothwell JC, Day BL, Marsden CD. Pathophysiology of blepharospasm and oromandibular dystonia. Brain 1985; 108:593-608.

25 Shibasaki H, Motomura S, Yamashita Y, Shii H, Kuroiwa Y. Periodic synchronous discharge and myoclonus in CreutzfeldtJakob disease: diagnostic application of jerk-locked averaging method. Ann Neurol 1981;9:150-6.

26 Marsden CD, Hallet M, Fahn S. The osology and pathophysiology of myoclonus. In: Marsden SD, Fahn S, eds. Movement Disorders, London, Butterworths, 1982:196-248.

27 Sunderland L. Pain mechanisms in causalgia. J Neurol Neurosurg Psychiatry 1976;39:471-80.

28 Schott GD. Induction of involuntary movements by peripheral trauma: an analogy with causalgia. Lancet 1986;ii:712-5. 